\title{
PELAKSANAAN PENGAWASAN PEKERJA WARGA NEGARA ASING DI PROVINSI BALI
}

\author{
Prabowo Wijayanto, I Nyoman Putu Budiartha, Desak Gede Dwi Arini \\ Fakultas Hukum Universitas Warmadewa, Denpasar-Bali, Indonesia
}

\begin{abstract}
Abstrak
Berdasarkan Peraturan Menteri Tenaga Kerja dan Transmigrasi Nomor 13 Tahun 2003 mengenai tenaga Kerja dan Transmigrasi. Banyaknya tenaga kerja asing yang bekerja di Bali, mengundang atensi dari pemerintah untuk melakukan pengawasan yang terukur dan terarah. Unutk terciptanya ketertiban administrasi, maka terbitlah peraturan yang berupa Izin untuk Mempekerjakan Tenaga Asing (IMTA). Penelitian ini bertujuan untuk mengetahui ketentuan hukum dan faktor yang terjadi terhadap pelaksanaan pengawasan pekerja Warga Negara Asing. Metode penelitian yang digunakan adalah hukum empiris yaitu dengan melakukan observasi dan wawancara langsung ke narsumber dalam hal ini adalah pekerja Disnaker terkait. Dari hasil pembahasan dan diskusi tentang proses pelaksanaan inspeksi ketenagakerjaan yang dilakukan oleh Dinas Tenaga Kerja Provinsi Bali untuk korporasi yang menggunakan pekerja asing melalui yang bekerja di wilayah Indonesia melalui Dinas Tenaga Kerja Provinsi Bali. Kemudian, faktor penghambat antara lain: pengguna TKA mengabaikan dengan sengaja tidak memperpanjang IMTA, kurangnya kerjasama antara kantor yang mengeluarkan izin untuk tinggal yakni kantor imigrasi dengan Disnaker Provinsi Bali atau Kemenakertrans sebagai lembaga yang mengeluarkan izin untuk mempekerjakan Pekerja Asing, pengawasan yang lemah dan fokus kontrol oleh Disnaker Provinsi setempat, program sosialisasi yang belum optimal disebabkan oleh tidak tersedianya anggaran dari Kementrian Tenaga Kerja dan Transmigrasi.
\end{abstract}

Kata Kunci: Pelaksanaan, Pengawasan, Tenaga Kerja Asing

\begin{abstract}
Based on the Regulation of the Minister of Manpower and Transmigration Number 13 of 2003 concerning Manpower and Transmigration. The large number of foreign workers working in Bali has invited the attention of the government to carry out measured and directed supervision. In order to create administrative order, a regulation in the form of a permit to employ foreign workers (IMTA) was issued. This study aims to determine the legal provisions and factors that occur in the implementation of the supervision of foreign workers. The research method used is empirical law, namely by making observations and direct interviews with the informants, in this case the related Disnaker workers. From the results of the discussion and discussion on the process of implementing the labor inspection carried out by the Bali Provincial Manpower Office for corporations that use foreign workers through those working in the territory of Indonesia through the Bali Provincial Manpower Office. Then, the inhibiting factors include: users of foreign workers deliberately neglecting not to extend the IMTA, lack of cooperation between offices that issue permits to stay, namely the immigration office with the Bali Provincial Manpower Office or the Ministry of Manpower as the agency that issues permits to employ foreign workers, weak supervision and focus of control by the local Provincial Disnaker, the socialization program has not been optimal due to the unavailability of budget from the Ministry of Manpower and Transmigration.
\end{abstract}

Keywords: Implementation, Supervision, Foreign Workers

\section{PENDAHULUAN}

Inspeksi ketenagakerjaan diperlukan untuk dapat mengambil langkah antisipatif dan mampu mengakomodasi semua perkembangan dalammenghadapi perubahan dalam nilai dan tata kelola industri dan perdagangan. Dengan denikian, perbaikan pada sistem ketenagakerjaan harus terus dilakukan sehingga aturan dapat diterapkan secara efektif. Pengawasan ketenagakerjaan sebagai alat membawa misi dan fungsi sehingga peraturan dapat ditegakkan. Dalam rangka untuk meningkatkan produktitivitas kerja dan kesejahteraan pekerja dapat jaminan maka harus menjaga keseimbangan antara hak dan kewajiban baik bagi pengusaha itu sendiri maupun pekerja sehingga kelangsungan bisnis dapat tercipta dengan baik dengan cara mengikuti aturan hukum yang sudah ada. 
Berkaitan dengan pengawasasan dan regulasi ketenagakerjaan khususnya pekerja asing, berikut ini beberapa penelitian telah mengkajinya seperti Antara, Putra, \& Ranawijaya (2016); Ang \& Fredriksson (2018); Athukorala \& Devadason (2012); Guo, Tang, \& Jin (2021); Kadfak \& Linke (2021); Roy (2021); Saad \& Fallah (2020). Untuk menciptakan kondisi yang kondusif maka pengembangan ketenagakerjaan harus teratur dan terarah sehingga hak dasar perlindungan bagi pekerja/ buruh terpenuhi pada saat yang bersamaan. Pengembangan lapangan kerja memiliki banyak dimensi dan keterkaitan. Keterkaitannya tidak hanya dengan kepentingan buruh selama, sebelum, dan setelah masa kerja, tetapi juga dalam kaitannya dengan kepentingan pelaku usaha, pemerintah, dan masyarakat. Oleh karenanya, Pengaturan yang komprehensif diperlukan untuk mengembangkan sumber daya manusia, meningkatkan produktivitas dan daya saing pekerja di Indonesia untuk memperluas ruang kerja, layanan pekerjaan dan membina hubungan industrial.

Menurut PERMEN Tenaga Kerja Nomor 3 Tahun 1990 mengenai Pemberian Izin didalam mempekerjakan tenaga kerja asing, yang berwenang ialah Petugas Inspeksi Tenaga Kerja Kementerian Tenaga Kerja untuk mengawasi pelaksanaan peraturan tentang pemberian izin untuk mempekerjakan pekerja asing migran, sebagaimana dinyatakan dalam Pasal 21 aturan ini (Budiono, 1999:276). Berdasarkan dari fakta hukum di atas, penelitian ini bertujuan untuk mengetahui proses pelaksanaan pengawasan Pekerja Asing yang dilakukan oleh Dinas Tenaga Kerja Provinsi Bali dan mengetahui faktor penghambat dalam Pelaksanaan Pengawasan di Disnaker Provinsi Bali.

\section{METODE PENELITIAN}

Penelitian ini menggunakan metode penelitian empiris yaitu penelitian langsung fokus pada suatu kejadian di lapangan atau keadaan dari objek penelitian dengan informasi data dari objek yang ada (Soekanto \& Mamudji, 2018). Dengan Penelitian Lapangan (field research), yaitu usaha-usaha untuk memperoleh bahan-bahan tulisan dan data dengan mengadakan wawancara langsung secara bebas yang dalam ini dilakukan di Dinas Tenaga Kerja Provinsi Bali untuk memperoleh informasi yang berhubungan dengan peran Badan Kepegawaian Daerah Provinsi Bali untuk menerapkan kebijakan Mentri Tenaga kerja terhadap penggunaan Tenaga Kerja Asing Di Bali. Sumber bahan hukum yang digunakan dalam penelitian ini meliputi 1) sumber data primer, yaitu data yang diperoleh di lapangan secara langsung dari Dinas Tenaga Kerja Provinsi Bali dengan melakukan wawancara kepada pihak terkait yang menangani objek penelitian ini. Kemudian, 2) sumber data sekunder, yaitu data yang diperoleh dari kepustakaan seperti dokumen-dokumen, artikel-artikel, makalah dan literatur hukum, khususnya yang terkait dengan objek penelitian. Teknik pengumpulan data dilakukan dengan dua cara, yaitu:

1. penelitian kepustakaan

Usaha untuk mengumpulkan data dengan cara membaca dan mempelajari serta mencatat halhal yang dianggap penting dan menyalin bahan-bahan berupa buku, Peraturan Perundangundangan, hasil penelitian, surat-surat keputusan maupun literatur-literatur lainnya yang berhubungan dengan permasalahan yang akan dibahas.

2. Penelitian Lapangan

a. Observasi: Penulis mendatangi lokasi penelitian.

b. Wawancara: Penulis melakukan tanya jawab secara langsung Staf Kepegawaian Dinas Tenaga Kerja Provinsi Bali.

c. Dokumentasi: Yaitu penulis melakukan pengumpulan data yang didapat di lokasi penelitian yang berhubungan.

\section{HASIL DAN PEMBAHASAN}

\section{Pelaksanaan Pengawasan Pekerja Warga Negara Asing di Diprovinsi Bali}

Manusia Indonesia merupakan aset bangsa dalam mengembangkan pembangunan nasional dan masyarakat. Dalam melaksanakan pembangunan nasional tenaga kerja merupakan salah satu pemegang peranan penting dalam menunjang keberhasilan pembangunan. Dalam menciptakan kesempatan kerja, kebijaksanaan ketenagakerjaan dalam program pembangunan selalu diutamakan guna untuk memantau ketertiban para pekerja. Dengan sumber daya manusia yang tertib maka dapat 
meningkatkan mutu di berbagai bidang usaha dan meningkatkan perlindungan terhadap tenaga kerja yang bersifat menyeluruh pada semua sektor.

Dengan meningkatnya perdagangan bebas dan global industri yang berkaitan dengan lapangan kerja membuat adanya tantangan dalam pembangunan nasional termasuk kehadiran para pekerja asing yang sudah menjadi kebutuhan yang tidak bisa dihindari karena Indonesia masih membutuhkan tenaga kerja asing dalam mengembangkan SDM di berbagai sektor industri maupun ekonomi. Munculnya masalah ketenagakerjaan di masa yang akan datang akan tumbuh semakin komplek sehingga membutuhkan penanganan yang lebih serius. Pergeseran nilai dan tata kelola akan terus terjadi selama masa pengembangan, pergeseran biasanya tidak jarang yang melanggar hukum dan peraturan yang berlaku.

Bidang ketenagakerjaan diperlukan untuk mengambil langkah antisipasi dan mengakomodasi perkembangan yang terjadi guna menghadapi perubahan nilai dan tata kelola industri yang ada. Oleh karena itu, perbaikan harus terus dilakukan pada sistem inspeksi ketenagakerjaan sehingga UU dapat diterapkan secara efektif pada perdagangan dan pelaku industri. Penerapan perundang-undangan juga dimaksudkan agar hak dan kewajiban masih terjaga dan seimbang baik bagi penngusaha maupun pekerja aar kelangsungan bisnis dan pekrjaan meningkat produktivitasnya dan para pekerja sejahtera.

Para pelaku industri dalam mengahadapi tata kehidupan dan pergeran nilai, para pengawas tenaga kerja dituntut untuk bisa mengambil langkah bijak dan antisipasi serta mampu mewadahi segala perkembangan yang ada saat ini. Karena itu, penyempurnaan terhadap sistem harus intens dilakukan agar aturan dapat dilaksanakan secara efektif oleh pelaku industri

Hak-hak dasar dan perlindungan ketenagakerjaan harus diatur dengan jelas sehingga baik pekerja/ buruh semua kebutuhan terpenuhi dan pada saat yang bersamaan dapat menciptakan kondisi yang kondusif bagi perkembangan dunia bisnis. Pengembangan lapangan kerja memiliki banyak dimensi dan keterkaitan diantaranya: keterkaitan tidak hanya dengan kepentingan buruh tetapi juga erat kaitannya dengan pengusha, pemerintah dan masyarakat. Pengaturan yang komprehensif diperlukan untuk mengembangkan SDM baik dalam produktivitas maupun daya saingnya, serta memperluas peluang kerja dan layanan pekerjaan dalam membina hubungan industri.

Untuk dapat mewujudkan industri yang harmonis, dinamis dan berkeadilan maka pembangunan ketenagakerjaan harus terarah dengan baik karena merupakan bagian dari hubungan industrial. Dalam bidang ketengakerjaan TAP MPR No. XVII/MPR/1998 harus diwujudkan guna untuk memberikan pengakuan dan penghargaan terhadap hak asasi manusia, ketetapan ini meruapakan tonggak untuk menegakkan demokrasi ditempat kerja.

Dalam pengertiannya Tenaga Kerja Asing adalah seseorang yang bukan berasal dari Negara Indonesia yang dapat melakukan pekerjaan baik di dalam maupun luar hubungan kerja, guna untuk menghasilkan barang/ jasa untuk memnuhi kebutuhan masyarakat. Arti Tenaga kerja asing itu sendiri dapat ditinjau dari berbagai sisi, salah satunya dapat menentukan kontribusi daerah dan juga menentukan status hukumnya serta bentuk persetujuan dari pengenaan retribusi (Khakim, 2009:27).

Baik investor maupun penanam modal asing wajib mentaati segala peraturan perundangundangan, mereka memicu kedatangan atau didatangkannya tenaga kerja asing. Pengaturan tenaga kerja asing diperlukan karena saling berkaitan baik dalam pengaturan aspek ketenagakerjaan maupun pengaturan aspek keimigrasian Indonesia. Dalam Pasal 42 ayat (1) Undang- Undang Nomor 13 Tahun 2003 tentang Ketenagakerjaan menjelaskan tenaga kerja asing harus mempunyai izin tertulis dari menteri atau pejabat yang ditunjuk dan berwenang. Oleh karena itu, pemberian kerja terhadap pekerja warga negara asing harus mengajukan rencana penggunaan tenaga kerja asing (RPTKA) dan izin mempekerjakan tenaga asing disebut IMTA.

Penggunaan tenaga kerja asing dalam wilayah republic Indonesia tentunya diatur dalam berbagai peraturan perundang-undangan, peraturan-peraturan tersebut yang menjadi dasar dalam penggunaan tenaga kerja asing (Abdussalam, 2008:32).

Untuk mengawasi penggunaan pekerja asing, perusahaan yang menggunakan pekerja asing harus terlebih dahulu membuat rencana penggunaan pekerja asing (RPTKA), yang secara khusus diatur oleh KEMENAKERTRANS No. PER-02 / MEN / III / 2008 tentang ketentuan penggunaan pekerja asing. Jika dilihat dari aspek hukum perburuhan tujuan dari peraturan ini adalah untuk memberikan jaminan dan kerja yang layak bagi warga negara terutama Indonesia di berbagai sektor atau bidang dan tingkatan. Sehingga dalam masuknya pekerja asing di Indonesia harus dilakukan dengan mekasnisme 
dan prosedur yang ketat mulai dengan seleksi, prosedur perizinan hingga pengawasan penggunaan pekerja asing tersebut. Ruang lingkup tugas pegawai ketenagakerjaan:

1. Melakukan pengawasan atas pelaksanaan peraturan yang berlaku mengenai keamanaan dan perlindungan para pekerja serta melaksanakan pembinaan.

2. Usaha untuk penyempurnaan aturan kerja dan pengawasan harus dilakukan pembinaanpembinaan.

3. Perlindungan untuk pekerja wanita, anak dan remaja dilakukan pembinaan dan pengawasan agar tidak terjadi hal dikemudian hari.

Sesuai dengan maksud diadakan pengawasan ketenagakerjaan, maka tugas utama dari pegawai pengawas sebagai berikut:

1. Pengawasan terhadap undang-undang dan peraturan yang berlaku.

2. Pengumpulan informasi, bahan dan keterangan soal keadaan tenaga kerja dan hubungan kerja dalam arti luas guna membuat UU dan peraturan ketenagakerjaan

3. Menyerahkan kepada UU dan peraturan-peraturan mengenai pekerjaan lain.

4. Pengawasan norma diperlukan dalam bidang kecelakaan kerja untuk melaksanakan usaha pembentukan.

Mengenai Izin Mempekerjakan Tenaga Kerja Asing (selanjutnya disebut IMTA), dan dijelaskan dalam Perda Provinsi Bali Nomor 5 Tahun 2013 dalam Pasal 1 angka 17 yang menyebutkan bahwa, IMTA merupakan izin yang diberikan kepada pemberi kerja TKA bersifat tertulis dan dapat diperpanjang, sesuai dengan PERMEN Ketenagakerjaan Indonesia Nomor 16 Tahun 2015 tentang penggunaan dan tata cara, jangka waktu berlakunya IMTA diberikan maksimal 1 tahun serta bisa diperpanjang sesuai dengan ketentuan yang berlaku yakni KEPMEN tentang jabatan yang dapat diduduki TKA tersebut, selanjutnya Permenaker No. 16 Tahun 2015 Pasal 40 juga menyebutkan, yang berwenang menerbitkan IMTA adalah Depnaker dan Transmigrasi RI yang dibayarkan sebesar 100/ bulan dalam hal perpanjangan IMTA, dimana pengajuannya berdasarkan bukti pembayaran DPKK (Dana Pengembangan Keahlian \& Ketrampilan Kerja), yang berwenang untuk melakukan perpanjangan IMTA ialah penerbit IMTA itu sendiri, dan dalam hal ini adalah Departemen Tenaga Kerja \& Transmigrasi RI, Permenaker No 16 Tahun 2015 Pasal 40 juga menentukan bahwa, penerbit IMTA lah, yang berwenang dalam melakukan pungutan izin perpanjangan IMTA itu sendiri, dan kemudian di setor ke Kas Daerah.

Perpanjangan IMTA digunakan untuk retribusi daerah, seperti yang dijelaskan dalam Peraturan Daerah Provinsi Bali Nomor 5 Tahun 2013 dalam Pasal 1 angka 19 menyatakan, Retribusi Perpanjangan IMTA adalah bentuk dari pembayaran untuk daerah, atas pemberian perpanjangan IMTA kepada pemberi kerja TKA Retribusi Perpanjangan IMTA termasuk dalam Retribusi Perizinan Tertentu tertuang dalam Pasal 2 Perda Provinsi Bali Nomor 5 Tahun 2013.

\section{Faktor penghambat dalam Pelaksanaan Pengawasan di Disnaker Provinsi Bali}

Pertama, ada beberapa faktor pendukung Dinas Tenaga Kerja Provinsi Bali dalam pengawasan tenaga kerja asing dikota Denpasar sebagai berikut:

a. Perusahaan jasa tenaga kerja asing memberikan data-data yang benar kepada Dinas Tenaga Kerja Kota Bandar Lampung terhadap calon Tenaga Kerja yang akan berkerja pada perusahaan di Kota Denpasar dalam hal ini adalah kebeneran memberikan data-data berupa dokumen-dokumen yang diperlukan oleh calon tenaga kerja asing.

b. Perusahaan yang memiliki tenaga kerja asing harus memberikan laporan kepada Dinas Tenaga Kerja Kota Denpasar terhadap kinerja tenaga kerja asing sehingga dapat menjamin pelaksanaan pengaturan dan pengawasan sesuai dengan peraturan ketenagakerjaan.

Berikut ini adalah faktor-faktor penghambat Dinas Tenaga Kerja Kota Denpasar dalam melakukan pengawasan Tenaga Kerja Asing di Kota Denpasar:

a. Disamping adanya kelalaian, pihak Pengguna TKA dengan sengaja tidak mengurus izin baik perpanjangan atau lainnya disebut dengan IMTA yang seharusnya adalah pihak perusahaan yang menggunakan TKA telah mengetahui dan mengingatkan pekerja asingnya untuk mengurus dan memperpanjang IMTA agar tidak terjadi masalah dikemudian hari.

b. Koordinasi yang kurang jelas antara Kantor Imigrasi sebagai penerbit Izin tinggal dengan Dinas Tenaga Kerja sebagai instansi atau yang mengeluarka IMTA. Pada dasarnya koordinasi 
dengan pihak terkait seharusnya dilakukan untuk menghindari adanya TKA yang ilegal di Provinsi Bali.

c. Kurang serta lemahnya pengawasan dalam mengendalikan TKA di wilayah Provinsi Bali oleh Dinas Tenaga Kerja dan Pihak terkait.

Pengawasan yang dilakukan oleh Dinas Tenaga Kerja Kota Denpasar hanya sebatas pada pengunaan IMTA oleh pengguna TKA, yaitu IMTA perpanjangan dan IMTA sementara, sehingga akan muncul berbagai indikasi pelanggaran pada penggunaan tenaga kerja asing dilapangan. Pengawasan yang dilakukan Oleh Disnaker Provinsi Bali biasanya hanya sebatas pada IMTA Perpanjangan dan IMTA sementara, pengunaan IMTA oleh Pekerja Asing, sehingga nantinya akan muncul beberapa indikasi pelanggaran pada penggunaan TKA dilapangan, pengawasan oleh pihak terkait pun harus diawasi agar berjalan tertib dan kondusif.

Unsur pengawasan ketenagakerjaan meruapakan salah satu unsur yang ikut berperan dalam mensejahterahkan, kesehatan dan keselamatan tenaga kerja. Segala masalah yang akan timbul bisa di deteksi sejak awal apabila penegak hukum di bidang pengawasannya bertindak sebagai pendeteksi dini dilapangan yang nantinya dapat memberikan atau mencipatakan suasana yang kondusif, stabil dibidang ketenagakerjaan dapat memantapkan dan memberikan partisipasi dalam melakukan pembangunan dan perkembangan nasional sehingga ekonomi dapat tumbuh dan berkembang sesuai harapan.

\section{SIMPULAN DAN SARAN}

\section{Simpulan}

Semua proses yang berjalan dibidang ketenagakerjaan yang dilakukan oleh kantor Disnaker Propinsi Bali terhadap korporasi dengan mengajukan izin mempekerjakan tenaga kerja asing, untuk kemudian dilakukan kepengurusan IMTA guna mendapatkan ijin, baik Pekerja asing maupun instansi terkait wajib memperhatikan peraturan ketenagakerjaan agar semua berjalan tertib, teratur dan terarah untuk mencegah hal buruk dikemudian hari. Kemudian, beberapa hambatan yang dialami dalam mendapatkan Izin mempekerjakan Tenaga Asing sebagai berikut ini:

a. Pengguna TKA mengabaikan,dan dengan sengaja tidak mengurus serta memperpanjang IMTA untuk para pekerjanya.

b. Koordinasi yang kurang baik antara instansi terkait yang dalam hal ini kantor imigrasi sebagai penerbit izin tinggal dan instansi yang mengeluarkan izin mempekerjakan pekerja asing dimana Depnakertrans yang mempunyai kewenangan.

c. Kurangnya pengendalian dan pengawasan oleh Pihak Terkait terhadap TKA yang bekerja terutama di Kota Denpasar.

d. Program sosialisasi yang belum maksimal disebabkan oleh anggaran yang tidak tersedia oleh Pihak Depnakertrans.

\section{Saran}

Melalui penelitian ini diharapkan kepada Dinas Tenaga Kerja Kota Denpasar, secara intens, melakukan perbaikan sistem data baik komputerisasi penerbitan IMTA yang dapat memontiring setiap IMTA yang akan habis jangka waktunya dengan cara melakukan perbaikan komputerisaiasi dalam menerbitkan IMTA. Selanjutnya, apabila terdapat indikasi pengurusan perpanjangan IMTA maka kepala Dinas Tenaga Kerja Kota Denpasar harus memberikan peringatan kepada perusahaan penggunaTKA. Terakhir, TKI harus menciptkan SDM yang mampu bersaing di semua bidang dan pekerjaan yang tersedia dari pemerintah, pengusaha dan investor baik dalam maupun luar negri yang dapat bekerjasama terutama dalam hal pelaksanaan pengawasan dan izin penempatan pkerja asing yaitu dilakukan membenahi diri dengan belajar serta berlatih sehingga tidak menimbulkan kerugian finansial.

\section{DAFTAR PUSTAKA}

Abdussalam, H. (2008). Hukum Ketenagakerjaan. Jakarta: Penerbit Restu Agung.

Ang, J. B., \& Fredriksson, P. G. (2018). Culture, Legal Heritage and the Regulation of Labor. Journal of Comparative Economics, 46(2), 616-633.

Antara, I. B. G. S. W., Putra, I. B. W., \& Ranawijaya, I. B. E. (2016). Harmonisasi Pengaturan Persyaratan Tenaga Kerja Asing dalam Skema Regulasi Asean Economic Community. Kertha Negara: Journal Ilmu 
Hukum, 4(6), 1-5.

Athukorala, P. chandra, \& Devadason, E. S. (2012). The Impact of Foreign Labor on Host Country Wages: The Experience of a Southern Host, Malaysia. World Development, 40(8), 1497-1510.

Budiono, A. R. (1999). Hukum Perburuhan di Indonesia. Jakarta: PT. Raja GrafindoPersada.

Guo, J., Tang, Q., \& Jin, G. (2021). Labor Protection and the Efficiency of Human Capital Investment. Economic Analysis and Policy, 69, 195-207.

Kadfak, A., \& Linke, S. (2021). More than Just a Carding System: Labour Implications of the EU's Illegal, Unreported and Unregulated (IUU) Fishing Policy in Thailand. Marine Policy, 127(September 2020), 1-9.

Khakim, A. (2009). Dasar-Dasar Hukum Ketenagakerjaan Indonesia. Bandung: Citra Aditya Bakti.

Roy, J. (2021). The effect of Employment Protection Legislation on International Trade. Economic Modelling, 94(September), 221-234.

Saad, A. F., \& Fallah, B. (2020). How Educational Choices Respond to Large Labor Market Shocks: Evidence from a Natural Experiment. Labour Economics, 66(August), 101901.

Soekanto, S., \& Mamudji, S. (2018). Penelitian Hukum Normatif: Suatu Tinjauan Singkat (18th ed.). Jakarta: Rajawali Pers. 